\title{
UMA ANÁLISE DA TEORIA CLÁSSICA DA ADMINISTRAÇÃO E SUA APLICABILIDADE EM UMA COOPERATIVA: UM ESTUDO NA COTRISEL
} AN ANALYSIS OF CLASSICAL THEORY OF MANAGEMENT AND ITS APPLICABILITY

IN A COOPERATIVE: A STUDY IN COTRISEL

Gustavo Fontinelli Rossés', Douglas Cavalheiro de Oliveira ${ }^{2}$, Marcelo Tomazi ${ }^{3}$ e Carla Rosane da Costa Sccott ${ }^{4}$

RECEBIDO EM: 20/12/2016 | APROVADO EM:16/04/2017

DOI: $10.5902 / 2317175825293$

\section{RESUMO}

O presente artigo tem por objetivo avaliar o grau de aplicabilidade dos princípios da teoria clássica da administração no processo decisório da Cooperativa Tritícola Sepeense Ltda (Cotrisel). Para tanto, realizou-se um estudo de caso de caráter qualitativo, com base nas dimensões exploratória e descritiva, sob a ótica de um estudo de caso acerca da teoria clássica, fundamentado nos 14 princípios de administração defendidos por Fayol. Em se tratando de eixo teórico, foram abordadas temáticas quanto às sociedades cooperativas e à teoria clássica da administração. Por meio da análise estatística descritiva, numérica e percentual, concluiu-se que a teoria clássica possui elevado grau de aplicabilidade na Cooperativa estudada. Os princípios que versam sobre "espírito de equipe", "ordem", "disciplina" e "centralização" foram os que apresentaram maior percentual de concordância, enquanto os que tratam da "unidade de comando", "remuneração", "unidade de direção" e "equidade" foram os que apresentaram percentual de concordância menor.

Palavras-chave: teoria clássica da administração, cooperativas, Cotrisel.

\footnotetext{
1 Doutor em Extensão Rural (UFSM). Mestre em Engenharia de Produção (UFSM). MBA em Gestão Empresarial (FGV). Graduado em Administração (UFSM). Profissional há 14 anos no mercado com atuação na Docência e nas áreas Administrativa, Comercial e de Marketing. E-mail: gustavo@politecnico.ufsm.br. 2 Graduado em Gestão de Cooperativas (UFSM). Atualmente cursa MBA em Gestão Estratégica do Agronegócio (ESCOOP) e atua como Supervisor Administrativo na Cooperativa Tritícola Sepeense Ltda - Cotrisel, desde 2007. E-mail: douglas@cotrisel.com.br.

3 Graduado em Agronomia (UFSM) e em Gestão de Cooperativas (UFSM). Atualmente Cursa Pós- Graduação em Engenharia de Segurança do Trabalho (UNIFRA) e é engenheiro agrônomo da Cooperativa Tritícola Sepeense Ltda, atuando desde 2001. E-mail: mtomazi@cotrisel.com.br.

4 Mestra em Engenharia de Produção (UFSM). Licenciatura Pedagógica para Educação Básica, Técnica e Tecnológica (UFSM). Graduação em Ciências Contábeis (UNIFRA). Contadora CRC/RS 090182/O. Atualmente é Professora do Instituto Federal Farroupilha - Campus Avançado de Uruguaiana. E-mail: carlasccott@gmail.com.
} 
UMA ANÁLISE DA TEORIA CLÁSSICA DA ADMINISTRAÇÃO E SUA

APLICABILIDADE EM UMA COOPERATIVA: UM ESTUDO NA COTRISEL

\begin{abstract}
The objective of this article is to evaluate the degree of applicability of the principles of the classical theory of management in the decision making process of Cooperativa Triticola Sepeense Ltda (Cotrisel). For that, a qualitative case study was carried out, based on the exploratory and descriptive dimensions, from the perspective of a case study, about the classical theory based on the 14 principles of administration defended by Fayol. In terms of the theoretical axis, thematic topics were covered regarding cooperative societies and the classical theory of administration. By means of the descriptive, numerical and percentage statistical analysis, it was concluded that the classical theory has a high degree of applicability in the studied Cooperative. The principles that deal with "team spirit", "order", "discipline", and "centralization" were those with the highest percentage of agreement, while those dealing with "command unit", "compensation", and "equity" were those that presented lower agreement percentage.
\end{abstract}

Keywords: classical theory of management, cooperatives, Cotrisel.

\title{
1 Introdução
}

O cooperativismo surgiu em meados do século XIX, tendo como berço a Inglaterra e a França. A doutrina cooperativista sofreu influências de socialistas como Owen, Fourrier, Mudie, Buchez, Blanc, Saint-Simon e Gide.

As cooperativas são associações autônomas de pessoas que se unem voluntariamente e constituem uma empresa, de propriedade comum, para satisfazer aspirações econômicas, sociais e culturais. Baseiam-se em valores de ajuda mútua, solidariedade, democracia, participação e autonomia. Os valores definem as motivações mais profundas do agir cooperativo, sendo a instância inspiradora dos princípios do Movimento Cooperativista Mundial (SCHMIDT; PERIUS, 2003 apud THUSEK, 2006, p. 2).

De acordo com a Organização das Cooperativas Brasileiras (OCB, 2015), a semente do cooperativismo foi lançada em 21 de dezembro de 1844, na cidade de Rochdale, Inglaterra, por meio da Sociedade dos Probos Pioneiros de Rochdale. O sucesso de "Rochdale" impulsionou os movimentos cooperativistas pelo mundo afora, contagiados pelos seus valores e princípios, que, com pequenas alterações, são amplamente adotados pelas cooperativas atuais. De acordo com a OCB (2015), em 2014 o Brasil possuía 1.548 cooperativas, 943.054 associados e 146.011 colaboradores.

As cooperativas possuem duas dimensões: social e econômica. No aspecto social, existem para trazer melhorias para seus cooperados. No econômico, necessitam de retorno financeiro para que sejam atingidos os interesses individuais de seus cooperados. É certo que, sem o econômico, não existe como manter o social. Conforme salientam Boesche e Mafioletti (2006), o cooperativismo precisa ser eficiente sem perder a finalidade social em relação aos associados, pois, na manutenção dessa dualidade associativa e empresarial, reside 
um dos maiores desafios do cooperativismo na atualidade.

O cooperativismo fortalece-se em resposta às dificuldades socioeconômicas, como um fator de inclusão social e como uma alternativa para que muitos se mantenham no mercado de trabalho. Com uma constituição jurídica própria, é uma alternativa para a organização do trabalho, principalmente na prestação de serviços e terceirização. A característica de não criar vínculo empregatício favorece sua competitividade e facilita sua atuação em vários setores da economia.

Os novos modos de gestão vêm se tornando um impulso para que os conceitos de participação nas tomadas de decisão e na estruturação de estratégias organizacionais que favorecem o diferencial competitivo das cooperativas sejam revistos. Acredita-se que a cooperativa se torna forte quando os cooperados assumem e usufruem dos seus serviços, pois a cooperativa é uma extensão de sua propriedade.

Com base nisso, percebe-se que o estudo das organizações e suas abordagens têm proporcionado ampliação de conhecimentos nas mais diversas áreas de atuação. Seu objetivo é oferecer ao administrador condições de estabelecer como se estrutura, como se coordena, como se gerencia e como são geridas as pessoas em uma organização.

Os processos administrativos utilizados nas empresas buscam suporte nas diferentes teorias desenvolvidas por experts. O estudo das teorias e seus princípios podem ajudar na resolução dos constantes problemas que surgem, devido ao ambiente em constantes transformações, com suas oportunidades e ameaças, forças e fraquezas. Quando princípios e técnicas de administração podem ser desenvolvidos, provados e utilizados, a eficiência administrativa inevitavelmente deve aumentar (KOONTZ; O'DONNEL; WEHRICH, 1986, p. 15).

Assim, a sociedade contemporânea, com seus complexos organizacionais e suas estruturas empresariais gigantescas, mais que nunca necessita dessa ciência, para gerenciar, organizar e controlar todo o processo das grandes e também das pequenas organizações, constituídas formalmente ou não, para que estas alcancem seus objetivos lucrativos, ou sociais, com eficiência e eficácia.

Diante disso, o objetivo deste estudo é avaliar a aplicabilidade dos princípios da teoria clássica nas atividades da Cooperativa Tritícola Sepeense Ltda (Cotrisel). Nesse sentido, dois objetivos específicos caracterizam este trabalho: identificar o que de fato pode ser considerado como característica particular de uma cooperativa que trabalha com base nos princípios da administração científica e averiguar como essas características influenciam a gestão e a operação dessa organização em especial.

Um estudo dessa natureza pode ser justificado por alguns elementos. 0 primeiro deles refere-se à importância de estudar as teorias da administração. Para Stoner e Freeman (2003, p. 22), "a teoria é um conjunto coerente de pres- 
UMA ANÁLISE DA TEORIA CLÁSSICA DA ADMINISTRAÇÃO E SUA

APLICABILIDADE EM UMA COOPERATIVA: UM ESTUDO NA COTRISEL

supostos elaborado para explicar as relações entre dois ou mais fatos observáveis e prover uma base sólida para se prever eventos futuros".

Para os mesmos autores, existem quatro razões para estudar as teorias administrativas: a) as teorias guiam as decisões da administração, pois o estudo das teorias auxilia a compreender os processos fundamentais e, com isso, permite prever o que irá acontecer em certas situações; b) as teorias dão forma à nossa visão das organizações, na medida em que mostram de onde se retiram algumas das ideias sobre as organizações e sobre as pessoas que participam delas; c) as teorias conscientizam-nos acerca do ambiente empresarial, pois cada teoria é produto do seu ambiente e adequada às circunstâncias vigentes; e d) as teorias são uma fonte de novas ideias, uma vez que possibilitam assumir um ponto de vista diferente com relação às situações do cotidiano, podendo coexistir conforme a necessidade e abrindo novos enfoques (STONER; FREEMAN, 2003).

Didaticamente, os estudiosos dividem linearmente as teorias da administração; no entanto, no dia a dia, as teorias fundem-se conforme as necessidades das organizações. Os princípios fundamentais das escolas científica e clássica denotados por Taylor, Fayol e Weber foram e serão sempre os pilares da evolução e do desenvolvimento da ciência da administração, motivando e impulsionando estudos, pesquisas, trabalhos e obras dos seus seguidores até os nossos dias.

A escolha por essa organização ocorreu, em nível amplo, em função da sua significativa importância econômica e social nos contextos local, regional e nacional. Em nível específico, a Cooperativa estudada apresenta-se como um caso de relativo sucesso quanto à gestão das suas atividades, o que sinaliza a presença de ganhos significativos. Esse fato foi considerado relevante para caracterizar essa Cooperativa como um caso salutar para identificar e compreender o funcionamento de suas rotinas.

Além disso, um estudo dessa natureza é relevante por ser diferenciado e propiciar a ampliação de conhecimentos no que tange à gestão eletrônica de documentos e suas funcionalidades nas cooperativas, bem como pela dimensão a ser estudada e pela disseminação dos resultados a serem gerados aos participantes.

Sendo assim, pretende-se, neste estudo, ampliar o conhecimento e a aplicabilidade da teoria clássica em cooperativas. Para isso, na seção 2, são fundamentados os aspectos referentes à teoria clássica por meio do referencial teórico. Nas seções 3 e 4, são apresentados os procedimentos metodológicos adotados, bem como o diagnóstico organizacional, na forma de estudo de caso. Finalmente, na seção 5, relatam-se as considerações finais.

\section{REFERENCIAL TEÓRICO}

As cooperativas são organizações autônomas constituídas mediante a adesão voluntária dos membros de determinado grupo social ou econômico que se juntam para alcançar seus objetivos e suas necessidades, por meio de uma sociedade de propriedade comum e democraticamente gerida. Elas são 
regulamentadas pela Lei.$^{\circ} 5.764$, de 16 de dezembro de 1971, que definiu a Política Nacional de Cooperativismo e instituiu o regime jurídico das cooperativas. Na visão de Perius (2007), as cooperativas são sociedades de pessoas que possuem natureza civil, não estão sujeitas à falência e são formadas com o objetivo de prestar serviços aos associados.

De acordo com a OCB (2015), as organizações cooperativas são guiadas pelos sete princípios do cooperativismo, sendo eles linhas orientadoras para a prática dos valores nas cooperativas. Para que mantivessem a dinâmica e condissessem com os novos tipos de cooperativas, os princípios foram revisados pela Aliança Cooperativa Internacional ( $(A C l)$ em 1937, 1966 e 1995, sendo esta a última revisão realizada e vigente até hoje em qualquer cooperativa do mundo. Os princípios são:

$\left.1^{\circ}\right)$ adesão livre e voluntária - as cooperativas são organizações voluntárias, abertas a todas as pessoas aptas a utilizar seus serviços e assumir responsabilidades como membros, que possuem o direito de se tornarem associados ou de se desassociarem quando quiserem. Engloba os valores de liberdade e igualdade;

$2^{\circ}$ ) gestão democrática - as cooperativas são organizações democráticas, controladas pelos seus membros, que participam ativamente na formulação das suas políticas e na tomada de decisões. Nas cooperativas, os membros têm igual direito de voto, ou seja, um membro vale um voto. Engloba os valores da democracia, da igualdade, da transparência e da responsabilidade;

$3^{\circ}$ ) participação econômica dos membros - os membros contribuem igualmente para o capital das cooperativas e o controlam democraticamente. Torna efetivos os valores da responsabilidade e da solidariedade;

$4^{\circ}$ ) autonomia e independência - as cooperativas são organizações autônomas, de ajuda mútua, controladas pelos cooperados. Em caso de firmarem acordos com outras organizações, incluindo instituições públicas, ou recorrerem a capital externo, devem fazê-lo em condições que assegurem o controle democrático pelos cooperados e mantenham a autonomia da sociedade. Refere-se aos valores da democracia, transparência e honestidade;

$5^{\circ}$ ) educação, formação e informação - as cooperativas promovem a educação e a formação dos seus membros, dos representantes eleitos e dos trabalhadores, de forma que estes possam contribuir, eficazmente, para o desenvolvimento das suas cooperativas, devendo ocupar-se de todos os valores;

$6^{\circ}$ ) intercooperação - as cooperativas servem de forma mais eficaz aos seus membros e dão mais força ao movimento cooperativo, trabalhando em conjunto, por meio das estruturas locais, regionais, nacionais e internacionais. Pratica-se o valor da solidariedade;

$7^{\circ}$ ) interesse pela comunidade - as cooperativas trabalham para o desenvolvimento sustentado das suas comunidades por meio de políticas aprovadas pelos membros. Associa-se diretamente ao valor da responsabilidade socioambiental. 
UMA ANÁLISE DA TEORIA CLÁSSICA DA ADMINISTRAÇÃO E SUA

APLICABILIDADE EM UMA COOPERATIVA: UM ESTUDO NA COTRISEL

Pautadas por esses princípios, as cooperativas procuram atuar em diferentes mercados, de modo que possam obter ganhos de escala e serem competitivas. Embora seja perceptível a relevância das cooperativas, cresce cada vez mais a concorrência com as demais organizações, sejam elas multinacionais, de capital fechado ou sociedades limitadas, o que intensifica a necessidade de um modelo de gestão coeso e efetivo. Zylbersztajn (1994) evidencia que o crescimento das estruturas cooperativas é seguido pela dificuldade de sua gestão.

De acordo com Gramacho (1997), rever seus produtos, suas estratégias e suas estruturas administrativas é uma ação que visa aumentar a eficácia e a competitividade das cooperativas. Desse modo, é necessário que essas organizações enfrentem os desafios dessa realidade mais complexa, sendo fundamental, para isso, a utilização de um modelo de gestão adequado.

A sociedade cooperativa é um empreendimento essencialmente econômico e não uma entidade assistencial. Nesse sentido, a mudança das relações no contexto econômico mundial reforça a necessidade das cooperativas adotarem, totalmente ou não, os mesmos métodos de administração utilizados atualmente pelas sociedades comerciais. Precisam incorporar, na prática, novas e eficientes técnicas ao seu sistema de gestão, sob o risco de não alcançarem os resultados sociais e econômicos essenciais para a satisfação dos cooperados. A busca por eficiência econômica nada tem de contraditório com os objetivos sociais da cooperativa: é uma questão de sobrevivência tanto da sociedade quanto dos sócios (NAVES, 1999 apud PANZUTTI, 2000, p. 5).

Diante disso, entende-se que, para dar a devida sustentação teórica para este trabalho, é necessário dedicar-se à investigação das questões pertinentes às teorias da administração, em especial no que concerne à teoria clássica da administração. Essa teoria foi idealizada pelo engenheiro francês Henri Fayol, pautada em 14 princípios claros e sistematizados. No entendimento de Montana e Charnov (2006), Fayol desenvolveu os princípios para guiar o gerente na resolução dos problemas do trabalho, pois entendia que os gerentes necessitavam de certas aptidões e habilidades que poderiam ser adquiridas.

Bateman e Snell (2000) assim enumeraram os 14 princípios: divisão do trabalho, autoridade, disciplina, unidade de comando, unidade de direção, subordinação do interesse individual ao interesse geral, remuneração, centralização, hierarquia, ordem, equidade, estabilidade de pessoal, iniciativa e espírito de equipe. O princípio da divisão do trabalho consiste em segmentar as tarefas elementares e destinar responsabilidades a indivíduos específicos (STONER; FREEMAN, 2003). Já a autoridade é o direito de exercer o poder dentro das organizações para obter obediência do colaborador e está intimamente ligada com responsabilidade: uma sem a outra leva ao fracasso (MONTANA; CHARNOV, 2006). 
Na concepção de Bateman e Snell (2000), a disciplina consiste em tornar as expectativas claras e punir as violações. Lacombe e Heilborn (2003) asseveram que disciplina é a aplicação de uma punição pela falta em agir, de acordo com a vontade da organização.

O princípio da unidade de comando, por sua vez, prevê que "cada trabalhador deve receber ordens de um único chefe, visão simplificada de uma organização que reduz conflito ao mínimo e promove clareza de comunicação" (MAXIMIANO, 2009, p. 40). Bateman e Snell (2000) advogam que a organização como um todo deve ter uma meta em comum e procurar realizar essa meta em todas as suas atividades, contemplando o princípio da unidade de direção. Corroborando esse princípio, Maximiano (2009) assinala que os esforços dos empregados devem se centrar no alcance dos objetivos organizacionais.

No que concerne à subordinação do interesse individual ao interesse geral, Montana e Charnov (2006, p. 20) afirmam que "a meta e os interesses da organização são mais importantes e prioritários do que as metas e os interesses pessoais do indivíduo". O princípio da remuneração diz que os trabaIhadores precisam ser recompensados pelos seus esforços de maneira justa. Para Bernardes e Marcondes (2003), o cálculo da remuneração deve considerar variáveis como: custo de vida, situação econômica geral, qualificação, oferta e procura por esses colaboradores e níveis de produtividade alcançados.

Bateman e Snell (2000) relatam que é necessário determinar a importância relativa do superior e do subordinado, atendendo ao princípio da centralização. A alta cúpula da empresa, bem como os gerentes, é responsável pelas decisões importantes. Aos subordinados devem ser delegados importantes encargos e autoridade suficiente para a realização da tarefa designada.

Os mesmos autores discorrem, ainda, sobre o princípio da hierarquia, segundo o qual cada indivíduo deve ocupar uma posição na estrutura hierárquica da empresa e ter a autoridade e responsabilidade necessárias para desenvolver o trabalho atribuído à sua função. "Com o objetivo essencial de organizar a colocação das coisas e das pessoas, Fayol obedece ao adágio simples: um lugar para cada coisa (pessoa), e cada coisa (pessoa) em seu lugar" (KOONTZ; O'DONNEL; WEHRICH, 1986, p. 51).

No entendimento de Montana e Charnov (2006), o princípio da equidade deve assegurar um tratamento igual e justo aos funcionários. Para tanto, são necessárias regras organizacionais consistentes e aplicáveis a todos os colaboradores. Além disso, os administradores devem ser amigáveis e justos para com seus subordinados.

A organização deve promover a lealdade e a longevidade do empregado, atendendo ao princípio da estabilidade e da manutenção do pessoal, já que uma alta taxa de rotatividade dos empregados estraga o funcionamento eficiente de uma organização (STONER; FREEMAN, 2003). Corroborando o princípio da iniciativa, Bernardes e Marcondes (2003) asseveram que a organização deve encorajar os empregados a agirem por eles mesmos no auxílio à 
UMA ANÁLISE DA TEORIA CLÁSSICA DA ADMINISTRAÇÃO E SUA

APLICABILIDADE EM UMA COOPERATIVA: UM ESTUDO NA COTRISEL

direção. Os subordinados devem ter a liberdade de conceber e concretizar seus planos, ainda que disso possam resultar alguns erros.

O último princípio de Fayol versa sobre o espírito de equipe. Lacombe e Heilborn (2003) revelam que a administração da empresa deve promover a harmonia e os interesses em comum, aspectos que resultam em boas relações entre os funcionários. A promoção de um espírito de equipe dará um sentido de unidade à organização. Para Fayol, até mesmo pequenos fatores podem ajudar a desenvolver esse espírito. Ele sugere, por exemplo, o uso, sempre que possível, da comunicação verbal, em vez da comunicação formal.

A seguir, no quadro 1, apresentam-se o eixo teórico e as principais categorias de análise que norteiam este estudo.

Quadro 1 - Conceitos norteadores da teoria clássica da administração

\begin{tabular}{|c|c|}
\hline Eixo teórico & Categorias de análise \\
\hline Teoria clássica da administração & $\begin{array}{c}\text { Divisão do trabalho } \\
\text { Autoridade } \\
\text { Disciplina } \\
\text { Unidade de comando } \\
\text { Unidade de direção } \\
\text { Subordinação do interesse individual ao bem comum } \\
\text { Remuneração } \\
\text { Centralização } \\
\text { Hierarquia } \\
\text { Ordem } \\
\text { Equidade } \\
\text { Estabilidade de pessoal } \\
\text { Iniciativa } \\
\text { Espinito de equipe }\end{array}$ \\
\hline
\end{tabular}

Fonte: adaptado de Bateman e Snell (2000), Montana e Charnov (2006) e Stoner e Freeman (2003).

Com base nesses elementos teóricos, assume-se, neste trabalho, o desafio de confrontar os aspectos destacados pelos autores supracitados com as práticas desenvolvidas na Cooperativa a ser estudada. Entende-se que tais elementos teóricos são essenciais e suficientes para servir de suporte à construção das categorias de análise, bem como necessários para atender aos objetivos da pesquisa.

\section{ASPECTOS METODOLÓGICOS}

Para atender aos objetivos e às finalidades deste trabalho, utilizou-se a perspectiva qualitativa. Stake (1983 apud CAMPOMAR, 1991, p. 96) assinala que "o uso de métodos qualitativos tem crescido em importância nas pesquisas acadêmicas em Administração e, entre eles, o estudo de caso merece destaque por sua utilidade e pela falta generalizada de conhecimento sobre essa metodologia".

Na pesquisa qualitativa, o cientista é ao mesmo tempo o sujeito e o objeto de suas pesquisas. O desenvolvimento da pesquisa é imprevisível. O conhecimento do pesquisador é parcial e limitado. $\mathrm{O}$ 
objetivo da amostra é de produzir informações aprofundadas e ilustrativas: seja ela pequena ou grande, o que importa é que ela seja capaz de produzir novas informaç̧ões (GOLDENBERG, 2007, p. 34).

Nesse sentido, esta pesquisa foca o caráter descritivo que, conforme Perovano (2014), visa à identificação, ao registro e à análise das características, dos fatores ou das variáveis que se relacionam com o fenômeno ou processo a ser estudado. Esse tipo de pesquisa pode ser entendido como um estudo de caso em que, após a coleta de dados, é realizada uma análise das relações entre as variáveis para uma posterior determinação dos efeitos resultantes em uma empresa, um sistema de produção ou um produto.

Quanto ao procedimento técnico, esta pesquisa apresenta características de um estudo de caso, o qual, segundo Gil (2009), é caracterizado pelo estudo profundo e exaustivo de um ou de poucos objetos, de maneira que permita o seu amplo e detalhado conhecimento. Yin (1990, apud CAMPOMAR, 1991, p. 96) corrobora essa ideia, afirmando que "o estudo de casos é uma forma de se fazer pesquisa social empírica ao investigar-se um fenômeno atual dentro de seu contexto de vida real, onde as fronteiras entre o fenômeno e o contexto não são claramente definidas e na situação em que múltiplas fontes de evidência são usadas".

Foram realizadas pesquisas bibliográficas, documentais e de campo. $\mathrm{Na}$ pesquisa bibliográfica, foram observados os seguintes aspectos: conceito de cooperativa, conceito e história do cooperativismo, cooperativismo agropecuário brasileiro e importância do estudo da teoria clássica da administração. Na pesquisa documental, buscaram-se dados da cooperativa em estudo, tais como: posição no mercado, balanço social e contábil, organograma, locais de atuação, principais produtos comercializados e número de funcionários. $\mathrm{Na}$ pesquisa de campo, definiu-se o envio de um questionário por e-mail para os funcionários, utilizando-se, para isso, de um formulário on-line, com as questões em estudo, confeccionado em um dos aplicativos do Google Docs (http:// docs.google.com). O questionário, constituído de perguntas estruturadas e abertas, teve a finalidade de conhecer a opinião dos funcionários acerca da aplicabilidade dos 14 princípios da teoria clássica na Cotrisel.

Enviou-se um questionário por e-mail, ressaltando aos funcionários que assinalassem apenas uma das alternativas nas proposições fechadas, não deixando respostas em branco. Nas questões abertas, os respondentes podiam efetuar considerações a respeito dos princípios da teoria clássica; no entanto, a resposta era facultativa. $O$ questionário foi aplicado com o consentimento da Cotrisel, garantido aos respondentes o sigilo e o anonimato das respostas. Trinta e cinco funcionários da Cooperativa participaram do estudo; fizeram parte da amostra da pesquisa colaboradores ligados aos níveis estratégico e tático da cooperativa. É preciso considerar, ainda, que a escolha dos participantes da pesquisa ocorreu com base na posição hierárquica que ocupam nas organizações onde atuam, no seu grau de influência e, ainda, na indicação de 
UMA ANÁLISE DA TEORIA CLÁSSICA DA ADMINISTRAÇÃO E SUA

APLICABILIDADE EM UMA COOPERATIVA: UM ESTUDO NA COTRISEL

membros devido à sua representatividade. Isso foi necessário, a fim de que pudessem, efetivamente, oferecer as respostas demandadas por este estudo, de modo a proporcionar maior credibilidade para essa etapa. A importância desse tipo de escolha remete ao fato de acreditar que esses profissionais entendessem, por completo, a dinâmica de atuação da organização e a condição de avaliar a aplicabilidade do modelo teórico do estudo.

$\mathrm{Na}$ análise dos dados, levou-se em consideração a metodologia utilizada por Fernandes et al. (2003), em que se atribuiu um valor numérico a cada possibilidade de resposta, de modo que, quanto maior fosse o escore, mais os respondentes estariam discordando da proposição elaborada e, quanto menor fosse esse valor atribuído, mais estariam concordando com a questão proposta. Os valores atribuídos variaram de 1 a 4, representados no Quadro 2, exposto a seguir.

Quadro 2 - Escala de respostas

\begin{tabular}{|c|c|c|c|}
\hline 1 & 2 & 3 & 4 \\
\hline $\begin{array}{c}\text { Concordo } \\
\text { plenamente }\end{array}$ & $\begin{array}{c}\text { Mais concordo que } \\
\text { discordo }\end{array}$ & $\begin{array}{c}\text { Mais discordo que } \\
\text { concordo }\end{array}$ & $\begin{array}{c}\text { Discordo } \\
\text { plenamente }\end{array}$ \\
\hline
\end{tabular}

Fonte: adaptado Fernandes et al. (2003, p. 163).

Após a coleta de dados, foi realizada uma análise estatística descritiva numérica e percentual, tendo como subsídio o referencial teórico sobre a teoria clássica da administração. A estatística descritiva, conforme Loesch (2012), tem a finalidade de resumir o conjunto de todos os dados coletados em dada investigação para relativamente poucos números e gráficos. Ela envolve basicamente distribuições de frequências, representações tabelares e gráficas, medidas de tendência central e de dispersão. A ideia básica foi estabelecer uma descrição dos dados relativos a cada uma das variáveis, dados esses levantados por meio de uma amostra. Essa técnica de análise dos resultados foi considerada importante, uma vez que sintetizou os valores de mesma natureza, apresentando-os de forma organizada para uma fácil compreensão dos resultados. Além disso, para a análise dos resultados. adotou-se a técnica de análise de conteúdo. Na visão de Silverman (2009), a análise do conteúdo é um método aceito de investigação textual e por isso pode ser utilizado por diferentes modelos de coleta. Existem várias formas de analisar o conteúdo; contudo, é importante verificar, inicialmente, o que se quer com as questões.

Para tanto, foi preciso que se criassem categorias de análise. Estas representam possíveis respostas para a pergunta realizada, podendo ser criadas com base nos dados coletados ou podendo ser preestabelecidas. Como colocam Olabuenaga e Ispizúa (1989), o processo de categorização deve ser entendido em sua essência como um processo de redução de dados. Assim, neste estudo, a categorização foi utilizada para agrupar dados considerando a parte comum existente entre eles. O Quadro 3, a seguir, apresenta o conjunto de categorias de análise necessárias para este estudo. 
Quadro 3 - Eixo teórico e categorias de análise

\begin{tabular}{|c|c|}
\hline Eixo teórico & Categorias de análise \\
\hline & Divisão do trabalho \\
& Autoridade \\
& Disciplina \\
& Unidade de comando \\
& Unidade de direção \\
Teoria clássica da administração & Rubordinação do interesse individual ao bem comum \\
& Remuneração \\
& Centralização \\
Hierarquia \\
Ordem \\
& Equidade \\
& Estabilidade de pessoal \\
Iniciativa \\
& Espinito de equipe \\
\hline
\end{tabular}

Fonte: adaptado Bateman e Snell (2000), Montana e Charnov (2006) e Stoner e Freeman (2003).

Dessa forma, entendeu-se que as categorias de análise estabelecidas permitiram identificar informações complementares sobre diferentes aspectos estudados quanto às características da teoria clássica da administração. A seguir, apresenta-se a Cooperativa onde foi realizado o estudo, descrevendo-se todos os aspectos necessários para compreender como ocorre a gestão eletrônica de documentos.

\section{DIAGNÓSTICO ORGANIZACIONAL}

O estudo de caso avaliou a aplicabilidade da teoria clássica da administração no processo decisório da Cotrisel. Fundada em 20 de setembro de 1957, na cidade de São Sepé, Rio Grande do Sul, a Cotrisel nasceu da dificuldade de comercialização do trigo, levando um pequeno grupo de agricultores a unir-se em torno da ideia do cooperativismo, como alternativa para a comercialização de seus produtos. Com o tempo, as doenças determinaram o abandono da cultura do trigo, fazendo com que a cooperativa passasse a receber, também, a produção orizícola. Era o começo da diversificação. Posteriormente, surgiu a soja, ocupando a infraestrutura montada para o recebimento do trigo. Atualmente, desponta como uma das maiores cooperativas arrecadadoras de tributos estaduais e federais da região e tem no arroz irrigado o carro-chefe de seus produtos, sem descuidar do recebimento de soja, trigo, sorgo, milho e feijão, produtos de grande importância econômica. $O$ arroz é responsável por aproximadamente $50 \%$ do faturamento da Cotrisel. Esse produto, após beneficiado, é comercializado com marca própria ("Sepé") para clientes dos estados de Espírito Santo, Rio de Janeiro, Minas Gerais e Bahia (COOPERATIVA TRITíCOLA SEPEENSE LTDA, 2016).

O confronto entre o referencial teórico e os aspectos metodológicos oportunizou a construção de um quadro de respostas que serviram de base para a apresentação dos resultados. Dessa forma, o Quadro 4, a seguir, tem como intuito oferecer esse suporte ilustrativo. 
UMA ANÁLISE DA TEORIA CLÁSSICA DA ADMINISTRAÇÃO E SUA

APLICABILIDADE EM UMA COOPERATIVA: UM ESTUDO NA COTRISEL

Quadro 4 - Somatória, média e percentual de concordância quanto aos princípios da teoria clássica da administração no processo decisório da Cotrisel

\begin{tabular}{|l|c|c|c|c|c|c|}
\hline \multicolumn{1}{|c|}{ Princípios } & Soma & Média & $\begin{array}{c}\text { Concordo } \\
\text { plenamente }\end{array}$ & $\begin{array}{c}\text { Mais } \\
\text { concordo } \\
\text { que } \\
\text { discordo }\end{array}$ & $\begin{array}{c}\text { Mais } \\
\text { discordo } \\
\text { que } \\
\text { concordo }\end{array}$ & $\begin{array}{c}\text { Discordo } \\
\text { plenamente }\end{array}$ \\
\hline 1. Divisão do trabalho & 59 & 1,69 & $43 \%$ & $46 \%$ & $11 \%$ & - \\
\hline 2. Autoridade & 55 & 1,57 & $57 \%$ & $31 \%$ & $9 \%$ & $3 \%$ \\
\hline 3. Disciplina & 43 & 1,23 & $80 \%$ & $17 \%$ & $3 \%$ & - \\
\hline 4. Unidade de comando & 70 & 2,00 & $34 \%$ & $40 \%$ & $17 \%$ & $9 \%$ \\
\hline 5. Unidade de direção & 62 & 1,77 & $46 \%$ & $34 \%$ & $17 \%$ & $3 \%$ \\
\hline $\begin{array}{l}\text { 6. Subordinação ao } \\
\text { interesse individual }\end{array}$ & 55 & 1,57 & $63 \%$ & $20 \%$ & $14 \%$ & $3 \%$ \\
\hline 7. Remuneração & 67 & 1,91 & $31 \%$ & $49 \%$ & $17 \%$ & $3 \%$ \\
\hline 8. Centralização & 48 & 1,37 & $66 \%$ & $31 \%$ & $3 \%$ & - \\
\hline 9. Hierarquia & 58 & 1,66 & $43 \%$ & $48 \%$ & $9 \%$ & - \\
\hline 10. Ordem & 42 & 1,20 & $83 \%$ & $14 \%$ & $3 \%$ & - \\
\hline 11. Equidade & 61 & 1,74 & $37 \%$ & $54 \%$ & $6 \%$ & $3 \%$ \\
\hline $\begin{array}{l}\text { 12. Estabilidade e } \\
\text { manutenção de pessoal }\end{array}$ & 48 & 1,37 & $69 \%$ & $28 \%$ & - & $3 \%$ \\
\hline 13. Iniciativa & 52 & 1,49 & $63 \%$ & $26 \%$ & $11 \%$ & - \\
\hline 14. Espírito de equipe & 41 & 1,17 & $83 \%$ & $17 \%$ & - & - \\
\hline \multicolumn{1}{|c|}{ Média } & - & $\mathbf{1 , 5 5}$ & $\mathbf{5 7 \%}$ & $\mathbf{3 2} \%$ & $\mathbf{9} \%$ & $\mathbf{2} \%$ \\
\hline
\end{tabular}

Fonte: dados da pesquisa.

Inicialmente, pode-se se constatar que, segundo os entrevistados e/ou pesquisados, há uma média que aponta para a concordância total ou parcial em relação a todos os itens pesquisados. Isso permite inferir que, do ponto de vista geral, há uma correlação evidente entre as características da teoria clássica da administração e as rotinas da Cooperativa investigada neste estudo. Tal fato pode ser percebido, ainda, pela média das respostas, que foi de 1,55, ou seja, entre 1 (concordo plenamente) e 2 (mais concordo que discordo), bem como pelo intervalo das respostas, que ficou entre 1,17 (menor) 2,00 (maior).

Além disso, verificou-se que a aplicação do princípio da "divisão do trabalho" obteve média de 1,69 , com $43 \%$ de concordância plena e $46 \%$ de concordância parcial. O percentual de inaplicabilidade desse princípio foi de $11 \%$. Essas informações oferecem suporte concreto para evidenciar a formalização das tarefas de acordo com seu grau de necessidade, de forma que a divisão do trabalho permite identificar os fatores críticos de sucesso na ação organizacional como um todo, bem como nas ações operacionais individuais. Tal ponto corrobora a ideia de Stoner e Freeman (2003), que apontam para a divisão do trabalho como um princípio importante para a teoria clássica da administração, uma vez que consiste em segmentar as tarefas elementares e destinar responsabilidades a indivíduos específicos.

Já o princípio da "autoridade" obteve média de 1,57, com 57\% de concordância plena, 31\% de concordância parcial e apenas 12\% de discordância. Essas informações demonstram a clareza visual da autoridade na estrutura organizacional e nas ações do dia a dia da Cooperativa, permitindo inferir que esse 
princípio tem alto grau de atendimento. Tais resultados evidenciam que, nas cooperativas, a autoridade deve ser legal, racional e burocrática, de modo que os subordinados aceitam como justificadas as ordens dos superiores, porque concordam com um conjunto de preceitos ou normas que consideram legítimos e do qual deriva o comando. Para Montana e Charnov (2006), a autoridade está intimamente ligada com responsabilidade; uma sem a outra leva ao fracasso.

O princípio da "disciplina", por sua vez, obteve média de 1,23. O resultado mostrou que $80 \%$ dos respondentes concordaram plenamente com a afirmativa de que a disciplina é preponderante para o bom desempenho das atividades do cotidiano. $O$ índice de concordância parcial foi de $17 \%$. Cerca de $70 \%$ dos respondentes entendem que a disciplina é boa, como se comprova nos seguintes comentários: "existe o respeito às regras" e "de modo geral é boa, os funcionários são preparados para conviver com as normas estabelecidas dentro da organização". A disciplina é boa dentro da Cooperativa, sendo muitas vezes decorrente da autoridade. No entanto, autoridade sozinha não leva a lugar nenhum. É indicado que se use o recurso da autoridade em último caso, quando todas as outras etapas (diálogo, conselho e hierarquia) tiverem sido vencidas.

O princípio da "unidade de comando" descreve que os empregados devem receber ordens de apenas um superior. Em relação a esse princípio, verificou-se média de 2, ou seja, um menor índice de concordância. Foram apenas $34 \%$ de concordantes plenos e $40 \%$ parciais. O percentual de discordância chegou a $26 \%$. Ficou constatado nas respostas que a aplicação desse princípio é um pouco difusa dentro da Cooperativa. Um respondente revelou que "existe para cada setor da cooperativa, no mínimo, mais de um que dá ordens, no entanto, sempre passa pelo gerente do setor. Acho que não deveria ser desse jeito, pois tem situações que o gerente fica sem saber o que fazer". Os pareceres citados externam a real situação encontrada na Cooperativa, onde os superiores são reconhecidos e respeitados, mas há, contudo, um excesso de pessoas com autoridade de mando, fato que em alguns casos acaba ocasionando conflito de ordens. Evidencia-se, assim, que o princípio da unidade de comando é aplicado, mas não em sua plenitude. Tais apontamentos deixam claro que não há uma total aplicação desse princípio na Cooperativa, pois, segundo Maximiano (2009, p. 40), "cada trabalhador deve receber ordens de um único chefe, visão simplificada de uma organização que reduz conflito ao mínimo e promove clareza de comunicação".

O princípio da "unidade de direção" obteve média de 1,77 , com $46 \%$ de concordantes plenos e $34 \%$ parciais. O percentual de discordância é de aproximadamente $20 \%$, sendo ocasionado pela limitação dos profissionais colocados no nível tático, dentre eles gerentes e supervisores, para tomar decisões mais abrangentes, tendo de se reportar seguidamente ao nível institucional. O princípio aplica-se, mas é fundamental ressaltar que a unidade de direção nos modelos atuais de administração tende a reforçar seus princípios, diante da necessidade cada vez maior de se trabalhar em função da unicidade de 
UMA ANÁLISE DA TEORIA CLÁSSICA DA ADMINISTRAÇÃO E SUA

APLICABILIDADE EM UMA COOPERATIVA: UM ESTUDO NA COTRISEL

objetivos. Bateman e Snell (2000) advogam que a organização como um todo deve ter uma meta em comum e procurar realizar essa meta em todas as suas atividades, contemplando o princípio da unidade de direção.

O princípio da "subordinação do interesse individual ao interesse geral" obteve média de 1,57, com $63 \%$ de concordância plena e $20 \%$ parcial. O percentual de inaplicabilidade foi de $17 \%$. Assim sendo, a grande maioria concorda que os interesses da organização são mais importantes e prioritários. No entanto, percebe-se que a principal dificuldade da Cooperativa está em equilibrar os interesses cooperativos, dos colaboradores e dos cooperados. Essa lógica implica a essência da proposta cooperativa, centrada nas questões econômicas e sociais. Para Montana e Charnov (2006, p. 20), "a meta e os interesses da organização são mais importantes e prioritários do que as metas e os interesses pessoais do indivíduo", pois a condição de proporcionar a alcance dos objetivos individuais está inicialmente pautada pelo atendimento dos objetivos organizacionais.

Com base no princípio da "remuneração", Fayol defendia a equidade, inferindo que é preciso o tratamento igual para pessoas iguais, a fim de justificar a lealdade e devoção dos funcionários quanto à organização. A média aferida foi de 1,91, contando com apenas $31 \%$ de concordantes plenos e $49 \%$ parciais. Nas respostas dos entrevistados, é perceptível certo desconforto perante os atuais critérios adotados: "às vezes o esforço individual não é reconhecido, dando espaço à acomodação de muitos", "a remuneração deveria ser conforme o grau de rendimento", "não aplica a justiça em todos os setores, alguns são mais privilegiados pelo plano de cargos" e "a questão é polêmica, os critérios remuneratórios às vezes contemplam as pessoas, às vezes a função ou simples aplicação do plano de cargos e salários". Esta última concepção reflete claramente a situação com que se depara a Cooperativa. O descontentamento acaba por ser evidente, mas deixa um questionamento extremamente complexo: qual é a maneira correta de definir a remuneração do colaborador? A esse respeito, Bernardes e Marcondes (2003) afirmam que o cálculo da remuneração deve considerar variáveis como: custo de vida, situação econômica geral, qualificação, oferta e procura por esses colaboradores e níveis de produtividade alcançados. Diante disso, entende-se haver a necessidade de fortalecer as condições econômicas de uma forma geral, para que estas sejam determinantes na capacidade de produção de riqueza por parte das organizações.

Por meio da "centralização", Fayol defende que todas as decisões importantes, as diretrizes, as normas e os procedimentos devem partir da alta administração da empresa. A média obtida foi de 1,37, de modo que $66 \%$ dos pesquisados concordaram plenamente e $31 \%$ parcialmente. O percentual de discordância foi de apenas 3\%. Isso denota alto grau de centralidade nas decisões, sendo necessário refletir sobre a importância da descentralização, que oferece maior necessidade de treinamento, emancipação do colaborador, motivação e envolvimento. Esses podem ser considerados pilares importantes para o crescimento e o desenvolvimento organizacional. 
Na verdade, quando se trata de uma cooperativa, pode-se constatar certa ambiguidade entre as temáticas da centralização e descentralização, já que as decisões sobre os rumos da cooperativa são tomadas exclusivamente nas assembleias. Tal fato é corroborado pelo princípio da gestão democrática, que prevê que as cooperativas são organizações democráticas, controladas pelos seus membros, que participam ativamente na formulação das suas políticas e na tomada de decisões. No entanto, é notório que a participação nas assembleias é bastante baixa, deixando explícito que poucos acabam tomando decisões por muitos. Conforme estudo de Fontes Filho, Marucci e Oliveira (2008), a participação dos associados em assembleias nas cooperativas no Brasil é baixa: $31 \%$ das respostas das cooperativas indicaram que menos de $5 \%$ dos associados assinaram a lista de presença na última assembleia; e $23 \%$ das respostas indicaram participação entre $5 \%$ e $10 \%$ dos associados. Assim, a maioria das cooperativas possui frequência menor que $10 \%$ na sua principal reunião.

O princípio da "hierarquia", por sua vez, corresponde aos diferentes níveis da estrutura organizacional da empresa, compreendendo desde o nível mais alto até o nível mais baixo. Nesse sentido, cada indivíduo deve ocupar uma posição na estrutura hierárquica da cooperativa e ter a autoridade e responsabilidade necessárias para desenvolver o trabalho atribuído à sua função. A média obtida foi de 1,66 , com $43 \%$ de concordantes plenos e $48 \%$ parciais. A discordância foi de $9 \%$. Na opinião dos entrevistados, a hierarquia é importante para definir as responsabilidades, bem como identificar as prioridades na execução das atividades, fatores esses percebidos como básicos para a boa operacionalidade organizacional.

O princípio da "ordem" possui grande relevância, pois se refere à organização na colocação de coisas e pessoas, entendendo que o desafio do administrador é encontrar a pessoa certa para o lugar certo. O estudo apontou média de 1,20 , com $83 \%$ dos respondentes concordando plenamente e $14 \%$, parcialmente. O percentual de inaplicabilidade foi de apenas $3 \%$. Por meio da questão aberta, 54\% dos respondentes revelaram que, na distribuição dos cargos, o material humano está alocado de maneira correta, tendo em vista o perfil exigido pelo cargo e o perfil do profissional. Isso vai ao encontro dos apontamentos de Koontz, O'Donnel e Wehrich (1986), ao destacarem que esse princípio visa ao correto destino dos recursos, para que se obtenha como resultado a diminuição de perdas de materiais e de tempo, bem como a otimização da mão de obra. A aceitação desse princípio é inegável devido à redução de custos propiciada pelo correto gerenciamento dos recursos materiais e humanos

Já o princípio da "equidade" defende tratamento igual para pessoas iguais, ou seja, pagamento igual para o mesmo tipo de trabalho. Essa proposição obteve média de 1,74 , contando com $37 \%$ de concordância plena e $54 \%$ de concordância parcial. Algumas colocações importantes são destacadas: "não sou da opinião que todos que trabalham no mesmo setor têm que receber o mesmo salário, devendo-se valorizar os interesses, o desprendimento e a 
UMA ANÁLISE DA TEORIA CLÁSSICA DA ADMINISTRAÇÃO E SUA

APLICABILIDADE EM UMA COOPERATIVA: UM ESTUDO NA COTRISEL

habilidade de desenvolver novos processos", "a motivação no desenvolvimento de suas tarefas também é importante, procurando entender e visualizar o trabalho de cada um por meio de seus gestores", "a avaliação de desempenho é uma boa ferramenta se bem administrada e observada, pois são várias opiniões sobre o profissional ou grupo de profissionais", "em primeiro lugar, para ter equidade de salário, os colaboradores devem ter o mesmo nível de comprometimento no trabalho" e "talvez não mereçam o mesmo salário se tiverem rendimento, empenho, qualidade e voluntariedade diferenciadas". Logo, ao confrontar o resultado da questão assertiva com as ponderações, foi possível aferir que a aplicabilidade desse princípio não é plena. Tais apontamentos evidenciam as ideias de Montana e Charnov (2006) sobre a equidade. Segundo esses autores, a equidade deve assegurar um tratamento igual e justo aos funcionários, e, para tanto, são necessárias regras organizacionais consistentes e aplicáveis a todos os colaboradores.

O princípio da "estabilidade e manutenção de pessoal" relata que a alta rotatividade de pessoal tem consequências negativas sobre o desempenho da organização e a moral dos trabalhadores. A média obtida foi de 1,37, com $69 \%$ de concordantes plenos e $28 \%$ parciais. Aqui é preciso evidenciar um ponto altamente positivo da Cooperativa, que faz um esforço considerável para a manutenção dos seus colaboradores, oferecendo treinamento constante, remuneração adequada ao mercado e construção de um clima organizacional favorável. Para Stoner e Freeman (2003), o princípio da estabilidade de pessoal visa evitar um fator muito indesejável na administração de recursos humanos: a rotatividade. Esse fator deve ser evitado pelas organizações, pois reflete um número elevado de demissões e admissões constantes que podem causar danos à imagem organizacional, pela perda de identidade humana e cultural.

Sobre o princípio da "iniciativa", foi elaborada uma questão fechada afirmando que os administradores devem "sacrificar sua vaidade pessoal" e permitir que seus subordinados possam exercer sua iniciativa. A média obtida foi de 1,49 , com $63 \%$ de concordância plena e $26 \%$ parcial. A discordância foi de $11 \%$. Para Stoner e Freeman (2003), esse princípio equilibra o princípio da centralização, de modo que se encontre a medida ideal para a delegação de poder e autoridade de acordo com cada tipo de organização. Para uma decisão certa, talvez no caminho haja decisões errôneas, mas essas não deverão ser motivo de desistência de obter êxito.

O último princípio descrito por Fayol trata do "espírito de equipe", ou seja, da busca da cooperação entre todos os funcionários da cooperativa para seu bom funcionamento. Essa proposição obteve média de 1,17, mostrando que $100 \%$ dos respondentes concordaram de maneira parcial ou plena que ter "espírito de equipe" é extremamente importante dentro da Cooperativa. Esse ponto positivo é considerado fundamental para favorecer o efeito sinergístico e impulsionar as ações individuais para a concretização dos objetivos da Cooperativa. Conforme Bernardes e Marcondes (2003), esse princípio é o reflexo de mais uma tendência 
antecipada por Fayol, pois as empresas atualmente despendem um esforço muito grande na área de recursos humanos para prover equipes na organização.

A partir dos dados analisados e descritos, é possível afirmar que a teoria clássica da administração possui alto grau de aplicabilidade nas rotinas diárias da Cotrisel. Todos os princípios da teoria se fazem presentes nos processos da Cooperativa; no entanto, no caso de muitos deles, a aplicação não é plena, visto que suas concepções são limitadas em alguns pontos e que a realidade organizacional está estruturada sobre os princípios mais flexíveis, abrangentes e modernos de administração. Mesmo assim, a teoria clássica aplica-se na Cotrisel.

Além disso, é preciso considerar que, em resposta à problemática levantada, os princípios de Fayol podem realmente ser aplicados na administração moderna e que, quanto à medida de aplicação, conforme o próprio Fayol já havia advertido, cada princípio não pode ser tratado de forma rígida e absoluta, sendo necessário guardar as devidas proporções na adoção de cada um deles.

\section{CONSIDERAÇÕES FINAIS}

A partir dos dados analisados e descritos, conclui-se que os objetivos deste estudo foram plenamente atingidos. A Cotrisel evidencia, em suas diretrizes e normas, a aplicação dos princípios da teoria clássica da administração, sendo sua presença percebida em todos os níveis da organização. Assim sendo, nota-se que os princípios da teoria clássica da administração possuem elevado grau de aplicabilidade na Cooperativa estudada, revelando percentual médio de $89,5 \%$ (concordantes plenos e concordantes parciais). Essa afirmativa é evidenciada pelo fato de que todos os princípios colocados em questão estão presentes de forma plena ou parcial na organização, sendo fatores influentes, e por vezes influenciados, nos processos da Cooperativa. Os princípios da teoria clássica que apresentaram maior grau de aplicabilidade na Cotrisel foram "espírito de equipe", "ordem", "disciplina" e "centralização", enquanto que os que tratam da "unidade de comando", "remuneração", "unidade de direção" e "equidade" foram os que apresentaram percentual de concordância menor.

Como consideração importante, entende-se que a realização deste trabalho oportunizou uma inegável comprovação de que os princípios de Fayol são perfeitamente aplicáveis na administração das organizações modernas. A profissionalização nas cooperativas é o caminho a ser seguido, sendo necessário que os gestores possuam elevado grau de conhecimento sobre o processo administrativo. Nesse sentido, as teorias administrativas assumem grande importância, e novos estudos deverão ser realizados a fim de permitir comparar as visões do gerente e de seus colaboradores em outras cooperativas agropecuárias. Para aprofundar os estudos sobre a aplicabilidade dos princípios da teoria clássica em cooperativas, recomenda-se, ainda, pesquisar mais intensamente os princípios que apresentaram maior discordância neste estudo.

A presente pesquisa abordou um tema ainda pouco difundido em estu- 
UMA ANÁLISE DA TEORIA CLÁSSICA DA ADMINISTRAÇÃO E SUA

APLICABILIDADE EM UMA COOPERATIVA: UM ESTUDO NA COTRISEL

dos cooperativistas, mas de extrema importância para as empresas cooperativas. Considera-se, assim, que este assunto não deve ser ignorado nas discussões das classes acadêmicas e profissionais relacionadas ao meio cooperativo.

Finalizando, cabe enfatizar que esta pesquisa não teve o propósito de exaurir os estudos ou tirar conclusões ousadas acerca de um tema tão importante como a implantação das teorias administrativas em cooperativas. Sendo assim, outras pesquisas poderão completar algumas lacunas deste estudo com o objetivo de expandir o nível de conhecimento sobre a temática, tanto em nível teórico quanto em nível prático.

\section{REFERÊNCIAS}

BATEMAN, T. S.; SNELL, S. A. Administração: construindo vantagem competitiva. São Paulo: Atlas, 2000.

BERNARDES, C.; MARCONDES, R. C. Teoria geral da administração. São Paulo: Saraiva, 2003

BOESCHE, L.; MAFIOLETTI, R. L. Evolução e indicadores do cooperativismo Brasileiro e Paranaense. Revista Negócios e Tecnologia da Informação, v. 1, n. 1, 2006. Curitiba/PR: SISTEMA OCEPAR, 2005. Disponível em: <http://publica.fesppr.br/index.php/rnti/article/view/v1n1ART6/90>. Acesso em: 25 mar. 2016.

CAMPOMAR, M. C. Do uso de 'estudo de caso' em pesquisas para dissertações e teses em administração. Revista de Administração: São Paulo, v. 26, n. 3, p. 95-97, jul./ago. 1991.

COTRISEL - Cooperativa Tritícola Sepeense Ltda. Histórico. Disponível em: <http://www.Cotrisel.com/empresa.php> Acesso em: 20 abr. 2016.

FERNANDES, M. S.; SPAGNOL, C. A.; TREVISAN, M. A. e HAYASHIDA, M. A conduta gerencial da enfermeira: um estudo de caso fundamentado nas teorias gerais da administração. Revista Latino Americana de Enfermagem: Ribeirão Preto, v. 11, n. 2, mar.-abr. 2003. Disponível em: <http://www.scielo.br/scielo. php?script=sci_arttextepid=S0104-11692003000200004elng=ptenrm=iso>. Acesso em: 11 jun. 2016.

FONTES FILHO, J. R.; MARUCCI, J. C. e OLIVEIRA, M. J. Governança cooperativa: participação e representatividade em cooperativas de crédito no Brasil. In: V Encontro de Pesquisadores Latino-americanos de Cooperativismo. Ribeirão Preto, São Paulo, 2008.

GIL, A. C. Estudo de caso. São Paulo: Atlas, 2009.

GOLDENBERG, M. A arte de pesquisar: como fazer pesquisa qualitativa em ciências sociais. Rio de Janeiro. Record. 2007.

GRAMACHO, A.. Cooperativas agrícolas e globalização. Agroanalysis, p. 14-15, ago. 1997.

KOONTZ, H.; O’DONNELL, C. e WEHRICH, H. Administração. São Paulo: Pioneira, 1986.

LACOMBE, F. e HEILBORN, F. Administração: princípios e tendências. São Paulo: Saraiva, 2003.

LOESCH, C. Estatística e probabilidades. Rio de Janeiro, LTC, 2012.

MAXIMIANO, A. C. A. Introdução à administração. São Paulo: Atlas, 2009.

MONTANA, P. J.; CHARNOV, B. H. Administração. São Paulo: Saraiva, 1997.

OCB - Organização das Cooperativas Brasileiras. Apresentação Institucional 2015. Brasília. Disponível em: <http:// www.ocb.org.br/site/cooperativismo/institucional.asp>. Acesso em: 25 jun. 2016.

OCB - Organização das Cooperativas Brasileiras. Apresentação História do Cooperativismo 2015. Brasília. Disponível em: <http://www.ocb.org.br/site/cooperativismo/historia.asp>. Acesso em: 25 jun. 2016.

OLABUENAGA, J. I. R.; ISPIZUA, M. A. La descodificacion de la vida cotidiana: metodos de investigación cualitativa. Bilbao: Universidad de deusto, 1989.

PANZUTI, R. et al. Cooperativa: uma empresa participativa. São Paulo: OCESP, 2000. 
PERIUS, V. F. Das sociedades cooperativas. In: KRUEGER, G.; MIRANDA, A. B. de (Coords.). Comentários à legislação das sociedades cooperativas. Belo Horizonte: Mandamentos, 2007.

PEROVANO, D. G. Manual de metodologia científica. São Paulo: Saraiva, 2014.

SILVERMAN, D. Interpretação de dados qualitativos. Porto Alegre: Artmed, 2009.

STONER, J. A. F. e FREEMAN, R. E. Administração. Rio de Janeiro: LTC - Livros Técnicos e Científicos Editora S. A., 2003.

THUSEK, C. N. L. Cultura da cooperação: uma abordagem psicossocial em uma cooperativa de trabalho. Revista Gestão e Tecnologia, v. 6, n. 1, 2006. Disponível em: <http://www.unipel.edu.br/periodicos/index.php/ get/article/viewFile/170/165>. Acesso em: 25 jun. 2016.

ZYLBERSZTAJN, D.. Organização de cooperativas: desafios e tendências. Revista de Administração de Empresas, São Paulo, v. 29, n. 3 p. 23-32, jul./ set. 1994. 